\title{
Essential childbirth and postnatal interventions for improved maternal and neonatal health
}

\author{
Rehana A Salam, Tarab Mansoor, Dania Mallick, Zohra S Lassi, Jai K Das, Zulfiqar A Bhutta*
}

\begin{abstract}
Childbirth and the postnatal period, spanning from right after birth to the following several weeks, presents a time in which the number of deaths reported still remain alarmingly high. Worldwide, about 800 women die from pregnancy- or childbirth-related complications daily while almost $75 \%$ of neonatal deaths occur within the first seven days of delivery and a vast majority of these occur in the first 24 hours. Unfortunately, this alarming trend of mortality persists, as 287,000 women lost their lives to pregnancy and childbirth related causes in 2010. Almost all of these deaths were preventable and occurred in low-resource settings, pointing towards dearth of adequate facilities in these parts of the world. The main objective of this paper is to review the evidence based childbirth and post natal interventions which have a beneficial impact on maternal and newborn outcomes. It is a compilation of existing, new and updated interventions designed to help physicians and policy makers and enable them to reduce the burden of maternal and neonatal morbidities and mortalities. Interventions during the post natal period that were found to be associated with a decrease in maternal and neonatal morbidity and mortality included: advice and support of family planning, support and promotion of early initiation and continued breastfeeding; thermal care or kangaroo mother care for preterm and/or low birth weight babies; hygienic care of umbilical cord and skin following delivery, training health personnel in basic neonatal resuscitation; and postnatal visits. Adequate delivery of these interventions is likely to bring an unprecedented decrease in the number of deaths reported during childbirth.
\end{abstract}

\section{Introduction}

The number of deaths reported during childbirth and postnatal period still remain alarmingly high. Worldwide, about 800 women die from pregnancy- or childbirth-related complications daily and approximately 287,000 women lost their lives to pregnancy and childbirth related causes in 2010 [1]. Every year an estimated 2.9 million babies die in the first 4 weeks of life [2,3]. Almost all (99\%) neonatal deaths occurs in low- and middle-income countries (LMICs), yet most epidemiological and other research focuses on mere $1 \%$ of deaths occurring in high income countries (HICs) [4]. The fact that almost all of these deaths were preventable and occurred in low-resource settings, points to a dearth of adequate facilities in these parts of the world. Preterm birth, birth asphyxia (lack of breathing at birth), and infections cause most neonatal deaths. The critical postpartum period starts from about an hour after the delivery of placenta and extends over the following

\footnotetext{
* Correspondence: zulfiqar.bhutta@aku.edu

Division of Women and Child Health, Aga Khan University, Karachi, Pakistan
}

six weeks. Postpartum care should respond to the special needs of the mother and baby during this critical period and should include prevention and early detection; treatment of complications and disease; attention to hygienic care; advice and support of exclusive breastfeeding; birth spacing; immunization; and maternal nutrition [5].

Since the postnatal period is a critical time to deliver interventions, failure to do so leads to detrimental effects on the survival and future health of both mother and neonate. Many women die as a result of complications during and following childbirth. The major complications that account for $80 \%$ of all maternal deaths are severe bleeding (mostly bleeding after childbirth), infections (usually after childbirth), high blood pressure during pregnancy (preeclampsia and eclampsia), and unsafe abortion. The remainder are caused by or associated with infectious diseases during pregnancy such as malaria and AIDS. A practical and viable strategy for reducing maternal and neonatal morbidity and mortality rates from preventable causes and meeting maternal health related Millennium Development Goal (MDG) targets, is by integrating 
improved childbirth facilities and postnatal care for newborns and mothers [6]. The $4^{\text {th }}$ MDG focuses on reducing child mortality and is closely associated with maternal health MDG. In developing countries alone, if mothers start practicing early initiation of breastfeeding, it is estimated that it can save as many as 1.45 million lives annually by reducing deaths mainly due to lower respiratory tract infections and diarrhoeal diseases [7]. To reduce the high burden of neonatal mortality and morbidity, postnatal care should be integrated into existing health programs. Community based education and health promotive workshops on exclusive breastfeeding and preventing vertical transmission of HIV will help increase the coverage of the postnatal interventions and improve maternal and newborn health.

This paper reviews and highlights the effectiveness of essential childbirth and immediate postnatal interventions for mothers and newborns during the parturition and postnatal period. This paper will help decision makers to deploy necessary interventions for improved maternal and newborn outcomes.

\section{Methodology}

The methodology has been described in detail elsewhere [8]. In short, the review included all childbirth and postnatal interventions based on current World Health Organization (WHO) guidelines and recent Lancet series which have an alleged impact on reducing maternal, neonatal and child mortality; suitable for delivery in LMICs; and those that can be delivered through the health sector (community level up to the referral level of health care) (Table 1). All relevant childbirth and postnatal intervention reviews were identified from the electronic databases such as the Cochrane database of systematic reviews, the Cochrane database of abstract reviews of effectiveness (DARE), the Cochrane database of systematic reviews of randomized control trials (RCT's), and PubMed. The reference lists of the reviews and recommendations from experts in the field were also used as sources to obtain additional publications. The principal focus was on the existing systematic reviews and meta-analysis. Based on the efficiency of the interventions, these were then classified in categories from $A$ to $E$ (where A signified strongly beneficial effect while $E$ indicated harmful effect) on different levels of health sector (community/outreach/referral).

\section{Childbirth interventions}

\section{Social support during childbirth}

Historically and cross-culturally, women have been attended and supported by other women during childbirth. However, since the middle of the 20th century, in many countries as the majority of women gave birth in hospital rather than at home, continuous support during labour has become an exception rather than the routine. Concerns about dehumanization of women's birth experiences (in high-, middle-, and low income countries) have led to calls for a return to continuous, one-to-one support by women for women during labour [9]. Common elements of this care include emotional support (continuous presence, reassurance and praise), information about labour progress and advice regarding coping techniques, comfort measures (such as comforting touch, massage, warm baths/showers, promoting adequate fluid intake and output) and advocacy (helping the woman articulate her wishes to others).

A systematic review by Hodnett et al. reported that women allocated to continuous support were more likely to have a spontaneous vaginal birth (risk ratio (RR) 1.08, 95\% confidence interval (CI) 1.04, 1.12) and less likely to have intrapartum analgesia (RR 0.90, 95\% CI 0.84, 0.97) or report dissatisfaction (RR $0.69,95 \%$ CI $0.59,0.79$ ). In addition their labour were shorter (mean difference (MD) -0.58 hours, $95 \%$ CI $-0.86,-0.30$ ), they were less likely to have a caesarean (RR $0.79,95 \%$ CI $0.67,0.92)$ or instrumental vaginal birth (RR $0.90,95 \%$ CI $0.84,0.96$ ), regional analgesia (RR $0.93,95 \%$ CI $0.88,0.99$ ), or a baby with a low 5-minute Apgar score (RR 0.70, 95\% CI 0.50, 0.96) [10]. Continuous social support has shown significant clinical benefits for women and infants. All women should receive continuous social support throughout labour and childbirth.

\section{Prophylactic antibiotic for caesarean sections}

The single most important risk factor for post-partum maternal infection is caesarean delivery [11]. Women undergoing caesarean section have a 5 to 20 -fold greater risk for infection compared with a vaginal delivery. Infectious complications that occur after caesarean delivery are an important and substantial cause of maternal morbidity and are associated with a significant increase in hospital stay [12]. Infectious complications following caesarean delivery include fever, wound infection, endometritis, bacteraemia, other serious infection (including pelvic abscess, septic shock, necrotizing fasciitis and septic pelvic vein thrombophlebitis) and urinary tract infection $[11,13,14]$. Fever can occur after any operative procedure and a low grade fever following a caesarean delivery may not necessarily be a marker of infection [15].

Prophylactic antibiotics in women undergoing caesarean section substantially reduce the incidence of febrile morbidity (RR 0.45 ; 95\% CI 0.39, 0.51), wound infection (RR 0.39; 95\% CI 0.32, 0.48), endometritis (RR 0.38; 95\% CI $0.34,0.42)$ and serious maternal infectious complications (RR 0.31; 95\% CI 0.19, 0.48) [16]. Based on these findings, we would recommend prophylactic antibiotics for women undergoing elective or non-elective caesarean sections however further studies are needed to explore potential adverse effects. 


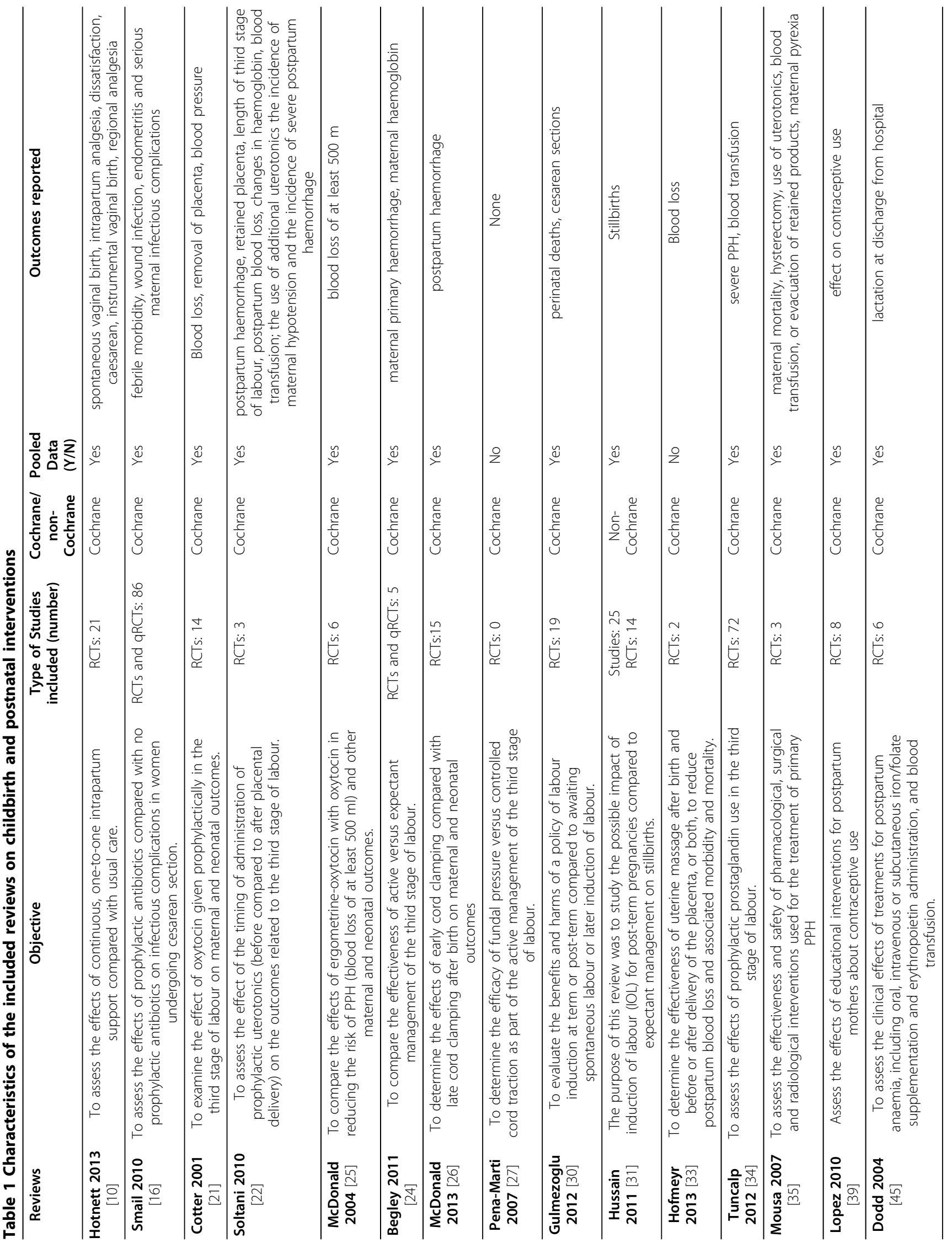




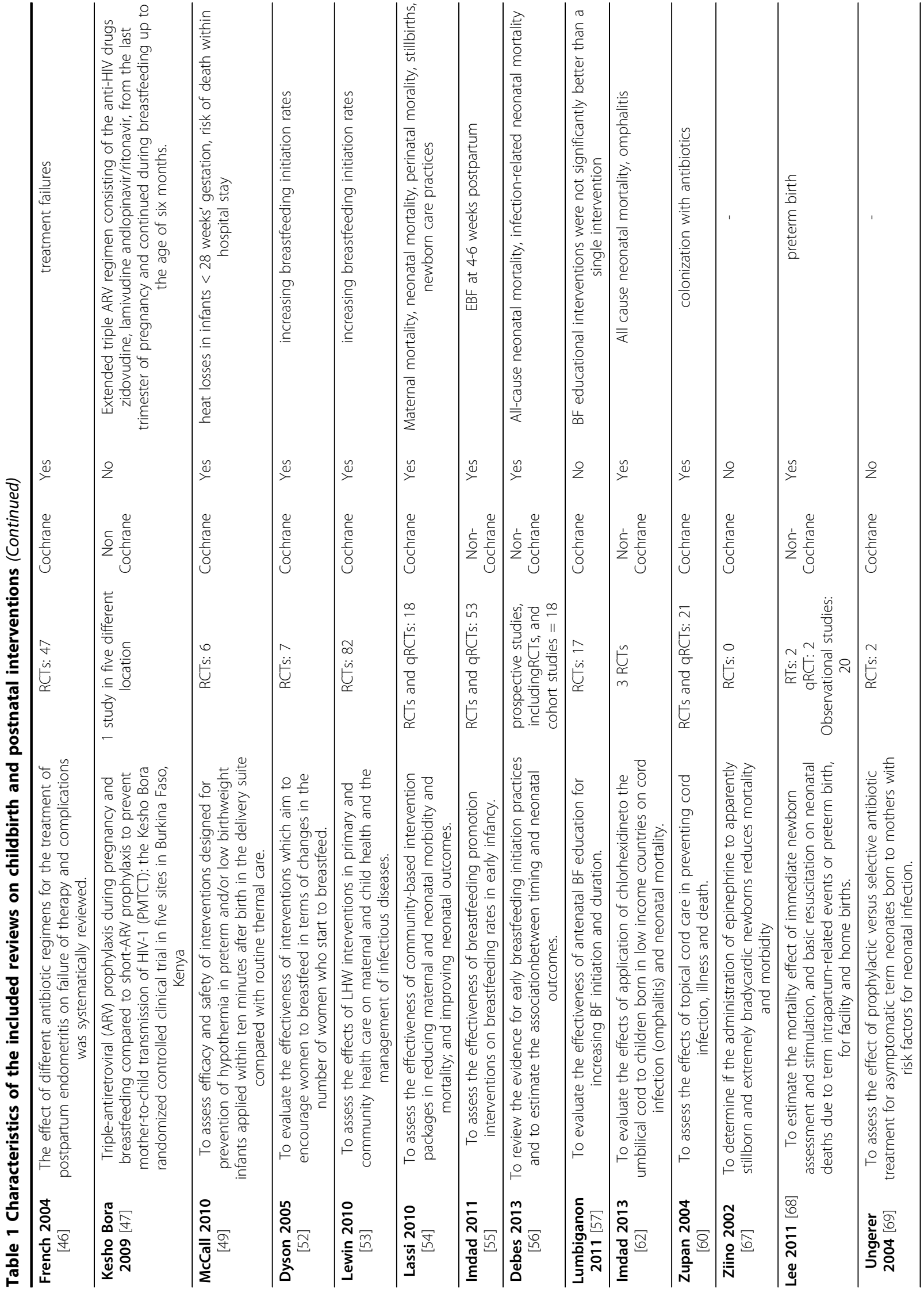




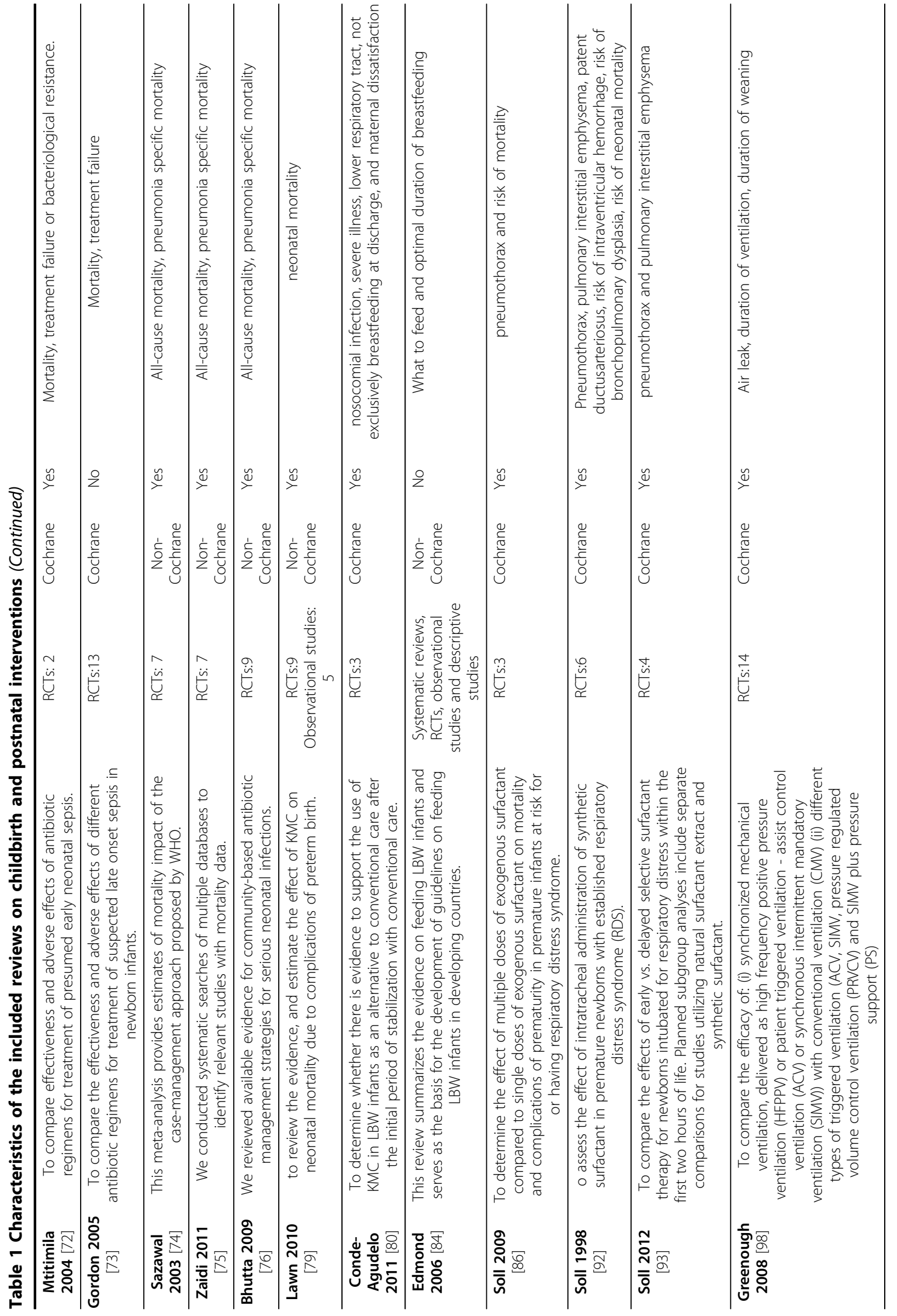




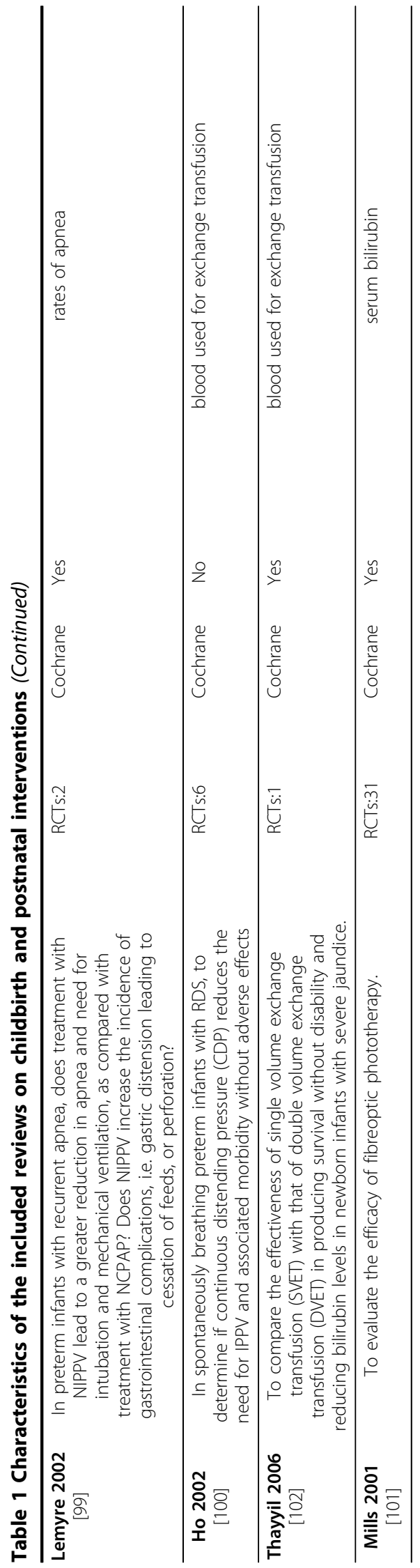




\section{Prevention of postpartum haemorrhage}

Excessive bleeding or postpartum haemorrhage (PPH) during or after childbirth is a life-threatening complication and a major contributor to maternal mortality worldwide [17]. Primary PPH is defined as heavy bleeding directly following childbirth or within 24 hours of thereafter [18]. One of the methods by which PPH is prevented is by active management of third stage of labour [19], while others include measures like uterine massage. Active management of third stage of labour (AMTSL) has three components which include the use of uterotonic agents, early cord clamping and controlled cord contraction. In 2012, the results of a large WHOdirected, multi-centre clinical trial [20] showed that administration of the uterotonic was the most important AMTSL component. This trial also demonstrated that the addition of Controlled Cord Traction had minimum effect on the reducing haemorrhage. Carbetocin (oxytocin) is a long acting synthetic analogue of oxytocin with pharmacological, clinical and agonist properties similar to oxytocin. It acts by combining to oxytocin receptors present in the uterus and causes increased tone and rhythmic contractions of the uterus and also increases the frequency of existing contractions.

\section{i) Oxytocin for PPH}

Prophylactic oxytocin showed benefits in reducing blood loss $>500 \mathrm{ml}$ (RR 0.50; 95\% CI 0.43, 0.59) and need for therapeutic oxytocics (RR 0.50; 95\% CI 0.39, 0.64) compared to no uterotonic [21]. While another review showed no influence of oxytocin before and after the expulsion of placenta on incidence of PPH (blood loss $>500 \mathrm{ml}$ ) (RR 0.81; 95\% CI 0.62, 1.04); retained placenta (RR 1.54, 95\% CI 0.76, 3.11); length of third stage of labour (minutes) (Mean difference (MD) -0.30, 95\% CI $-0.95,0.36$ ); postpartum blood loss (ml) (MD 22.32, 95\% CI $-58.21,102.86)$; changes in haemoglobin $(\mathrm{g} / \mathrm{dL})$ (MD $0.06,95 \%$ CI $-0.60,0.72$ ); blood transfusion (RR 0.79, 95\% CI $0.23,2.73$ ); use of additional uterotonic (RR 1.10, $95 \%$ CI $0.80,1.52$ ); incidence of maternal hypotension (RR $2.48,95 \%$ CI $0.23,26.70$ ) and incidence of severe $\mathrm{PPH}$ (blood loss $\geq 1000 \mathrm{ml}$ ) (RR 0.98, 95\% CI 0.48, 1.98) [22].

\section{i) Active management of third stage of labour}

In this section we included reviews that compared AMTSL with expectant management (when the placenta is allowed to deliver spontaneously or aided by gravity and nipple stimulation). According to the latest guideline of WHO, AMTSL as a prophylactic intervention is composed of three steps: 1) administration of a uterotonic, preferably oxytocin, immediately after birth of the baby; 2) controlled cord traction (CCT) to deliver the placenta; and 3) massage of the uterine fundus after the placenta is delivered. In 2012, the results of a large WHO-directed, multi-centre clinical trial [20] showed that the most important AMTSL component was the administration of the uterotonic. In view of the data from this trial and the existing evidence concerning the role of routine uterine massage in the prevention of PPH, the WHO issued new recommendations which state that although administration of a uterotonic remains central to the implementation of AMTSL, the performance of CCT and immediate fundal massage are optional components [23].

Active management of third stage of labor showed reduction in the risk of haemorrhage at time of birth $(>1000 \mathrm{ml})(\mathrm{RR} 0.34,95 \%$ CI $0.14,0.87)$ and of maternal haemoglobin $(\mathrm{Hb})<9 \mathrm{~g} / \mathrm{dL}$ following birth (RR 0.50, 95\% CI 0.30, 0.83) [24]. Compared with oxytocin, ergometrineoxytocin was associated with a small reduction in the risk of PPH (OR 0.82, 95\% CI 0.71, 0.95) [25]. On the other hand, no significant differences were found between early versus late cord clamping on severe PPH (RR 1.04, 95\% CI $0.65,1.65)$ or for PPH $(>500 \mathrm{ml})$ (RR $1.1795 \%$ CI 0.94 , 1.44) [26]. Another review by Pena-Marti et al. did not find studies that compared fundal pressure versus controlled cord traction as part of AMSTL [27]. These findings suggest active management is superior to expectant management in terms of reduction in the risk of maternal haemorrhage at time of birth. However, statistically significant results in the improved outcomes of blood loss and $\mathrm{PPH}$ could not be found when active management was employed. On the other hand, prophylactic oxytocin showed benefits in reducing blood loss $>500 \mathrm{ml}$ and need for therapeutic oxytocics.

\section{Induction of prolonged pregnancy}

Five to ten percent of pregnancies continue beyond 294 days (42 completed weeks) and are described as being 'post-term' or 'postdate' [28]. Both the mother and the infant are at increased risk of adverse events when the pregnancy continues beyond term [29]. Hilder et al. 1998 reported that after 41 weeks, neonatal and post neonatal death risk increased significantly. The obstetric problems associated with post-term pregnancy include induction of labour with an unfavourable cervix, caesarean section, prolonged labour, PPH and traumatic birth. It is likely that some of these unwanted outcomes result from intervening when the uterus and cervix are not ready for labour [29].

Compared with a policy of expectant management, a policy of labour induction was associated with fewer (allcause) perinatal deaths (RR 0.31, 95\% CI 0.12, 0.88). The number needed to treat to benefit (NNTB) with induction of labour in order to prevent one perinatal death was 410 (95\% CI 322, 1492) [30]. Another meta-analysis of trials also suggested that a policy of elective induction of labour for pregnancies at or beyond 41 weeks is associated with significantly fewer perinatal deaths (RR 0.31; $95 \%$ CI: 0.11 , 0.88) compared to expectant management, but no significant difference in the incidence of stillbirth (RR 0.29; 95\% CI: $0.06,1.38$ ) was noted. There was significant decrease in incidence of neonatal morbidity from meconium aspiration 
(RR 0.43, 95\% CI 0.23, 0.79) and macrosomia (RR 0.72; 95\% CI: 0.54, 0.98) [31]. In case of absence of a specific disorder, induction of labour can be proposed in patients between $41(+0)$ and $42(+6)$ weeks (grade B). It is important to convey to the decision makers and patients that the choice of prolonging beyond $42(+0)$ weeks appears to involve an increase risk and decision should be weighed and balanced against the potential disadvantages of induction (Professional consensus). Stripping the membranes can reduce the duration of pregnancy by increasing the number of patients going into labour spontaneously during the week afterward (grade B) [32]. This policy is associated with fewer deaths. There does not seem to be any increased risk of assisted vaginal or abdominal delivery. If the woman chooses to wait for spontaneous labour onset it would be prudent to have regular fetal monitoring as longitudinal epidemiological studies suggest increased risk of perinatal death by increasing gestational age.

\section{Management of postpartum haemorrhage}

Primary PPH requires a multidisciplinary approach. First line treatment is with uterotonic (such as ergometrine, oxytocin, prostaglandins) accompanied with bimanual compression of the uterus. The second line therapy is surgical, usually hysterectomy to prevent death from uterine haemorrhage.

\section{i) Uterine massage}

The review by Hofmeyr et al. included two randomised controlled trials [33]. The first trial randomised women to receive uterine massage or no massage following delivery of the placenta, after active management of the third stage of labour including use of oxytocin. The numbers of women with blood loss $>500 \mathrm{ml}$ was small, with no difference (RR 0.52 , 95\% CI $0.16,1.67$ ) while the mean blood loss was significantly less in the uterine massage group at 30 minutes (MD -41.60ml, 95\% CI -75.16, -8.04) and 60 minutes (MD -77.40ml, 95\% CI -118.71, -36.09). There were no cases of retained placenta in either group.. The need for additional uterotonic was also significantly reduced in the uterine massage group (RR 0.20, 95\% CI $0.08,0.50)$. For use of uterine massage before and after delivery of the placenta, another trial assigned women to receive oxytocin, uterine massage or both after delivery of the baby but before delivery of the placenta. There was no added benefit for uterine massage plus oxytocin over oxytocin alone with respect to blood loss $\geq 500 \mathrm{ml}$ (RR $1.56,95 \%$ CI $0.44,5.49$ ) or need for additional use of uterotonic (RR 1.02, 95\% CI 0.56, 1.85) [33].

\section{ii) Use of uterotonic}

Oral or sublingual misoprostol when compared with placebo was found to be effective in reducing severe $\mathrm{PPH}$ (sublingual: RR 0.66; 95\% CI 0.45, 0.98) and blood transfusion (oral: RR 0.31; 95\% CI 0.10, 0.94). Compared with conventional injectable uterotonic, oral misoprostol was associated with higher risk of severe PPH (RR 1.33; 95\%
CI 1.16, 1.52) and use of additional uterotonic, but with a trend towards fewer blood transfusions (RR 0.84; 95\% CI $0.66,1.06)$ [34]. The comparison of misoprostol (dose 600$1000 \mathrm{mcg}$ ) with placebo did not show any impact on reducing maternal mortality (RR 7.24, 95\% CI 0.38, 138.6), hysterectomy (RR 1.24, 95\% CI 0.04, 40.78), additional use of uterotonic (RR 0.98, 95\% CI 0.78, 1.24), blood transfusion (RR 1.33, 95\% CI 0.81, 2.18), or evacuation of retained products (RR 5.17, 95\% CI 0.25, 107). Misoprostol use was associated with a significant increase in maternal pyrexia (RR 6.40, 95\% CI 1.71, 23.96) and shivering (RR 2.31, 95\% CI 1.68, 3.18) [35]. These findings suggest that misoprostol is effective in reducing severe $\mathrm{PPH}$ and blood transfusion. In comparison with conventional injectable uterotonic, oral misoprostol was associated with higher risk of severe $\mathrm{PPH}$ and use of additional uterotonic, but with a trend to fewer blood transfusions.

\section{Postnatal (mother) \\ Advice and provision of family planning}

The provision of contraceptive education is now considered a standard component of postpartum care. Family planning advice and education about contraception are commonly provided to women who have just given birth and is frequently provided as part of discharge planning [36]. Decisions about contraception made right after counseling may differ considerably from contraceptive use postpartum [37]. As common as postpartum contraceptive education has become, research to evaluate such interventions is still sparse [38].

Oral contraceptive education program (one time) versus routine counselling led to a decrease in the incidence of known pregnancy by one year (odds ratio (OR) 0.81; 95\% CI: $0.11,6.04)$, increase in the rate of continuation of oral contraceptives at one year (OR 0.67; 95\% CI: 0.11, 3.99) and a greater chance of switched contraceptives by one year(OR 2.0; 95\% CI: 0.37, 10.92) [39]. Contraceptive counseling (one time) versus no counseling led to an increase in the use of any contraceptive at 8 to12 weeks postpartum (OR 19.56; 95\% CI: 11.65, 32.83) and an increase in the choice of modern contraceptive (using or plan to use) at 8 to 12 weeks postpartum (OR 1038.09; 95\% CI: 64.15,16799.73) [39]. Health education including contraception with an immediate session versus no immediate session increased the use of contraception at 3 months (OR 1.50; 95\% CI: 0.88, 2.54) and at 6 months (OR 1.62; 95\% CI: 1.06, 2.50) [39]. After a later session versus no session, use of contraception at 6 months did not increase significantly (OR 0.95; 95\% CI: 0.50, 1.80). Special postpartum care (including contraception) versus routine services (multiple well-baby contacts) led to decreased incidence of a repeat pregnancy (self-report) by 18 months (OR 0.35; 95\% CI: 0.17, 0.70) [39]. These findings suggest that postpartum education about contraception leads to 
more contraception use and fewer unplanned pregnancies. Such education may be effective in increasing the shortterm use of contraception. However, there are only limited data examining a more important longer-term effect on the prevention of unplanned pregnancies.

\section{Detection and treatment of maternal anaemia}

Anaemia after the birth of a baby (postpartum anaemia) is a common problem throughout the world and for most women is self-limiting, resolving within a week [40]. For some women however, particularly in resource-poor countries, it is a major cause of maternal morbidity (poor health) and mortality [41-43]. In this setting, anaemia may result from inadequate dietary intake, parasitic infection or malaria, and may be exacerbated by the physiological effects of pregnancy and blood loss at the time of birth [44]. Traditional treatments include iron supplementation and blood transfusion for severe anaemia. A hormone, erythropoietin, may help improve iron levels in the blood and the woman's ability to lactate.

When compared with iron therapy only, erythropoietin increases the likelihood of lactation at discharge (RR 1.90; 95\% CI: $1.21,2.98)$ and decrease the need for blood transfusion (RR 0.20; 95\% CI: 0.01, 3.92) [45].However, the review did not identify any trial that assessed treatment with blood transfusion. Currently, limited evidence exists for the treatment of anaemia with erythropoiten and high quality trails are needed to assess the treatment of postpartum anaemia with iron supplementation and blood transfusion.

\section{Detection and management of postpartum sepsis}

Inflammation of the lining of the womb (postpartum endometritis), also known as puerperal fever, is caused by infection entering the womb (uterus) during childbirth. It occurs in about 1 to $3 \%$ of births, and is up to ten times more common after caesarean section. Prolonged rupture of membranes and multiple vaginal examinations also increase the risk. Endometritis causes fever, uterine tenderness and unpleasant-smelling lochia, and it can have serious complications such as abscess formation, sepsis and blood clots. It is also an important cause of maternal mortality worldwide, although this is very rare in HICs with the use of antibiotics.

Fifteen studies comparing clindamycin and aminoglycoside with another regimen found more treatment failures with the other regimen (RR 1.44; 95\% CI 1.15, 1.80). Failures of those regimens with poor activity against penicillin resistant anaerobic bacteria were more likely (RR 1.94; 95\% CI 1.38, 2.72) [46]. The combination of gentamicin and clindamycin appears suitable for the treatment of endometritis while regimens with activity against penicillin resistant anaerobic bacteria are better than those without them.

\section{Screening and initiation or continuation of antiretroviral therapy for HIV}

Antiretroviral (ARV) drugs reduce viral replication and can reduce mother-to-child transmission of HIV either by lowering plasma viral load in pregnant women or through post-exposure prophylaxis in their newborns. In HICs, highly active antiretroviral therapy (HAART) which usually comprises three drugs has reduced the mother-tochild transmission rates to around 1-2\%. Recent evidence published in Lancet Infectious Diseases based on the Kesho Bora Studies shows that giving a combination of three ARV drugs to pregnant mothers with HIV infection from the last trimester, through delivery and six months of breastfeeding reduces the risk of transmitting HIV to the baby and improves survival. Infants of mothers whose virus is fully suppressed (undetectable) by triple-ARVs at the time of delivery have a very low risk of HIV infection (only $2.7 \%$ by the age of one year).It is therefore important to start ARVs early in pregnancy, ideally before pregnancy, for all women who require ART (CD4 count at or below 350 cells $/ \mathrm{mm} 3)$.

The Kesho Bora study shows that a significant reduction in infant infection can be achieved when pregnant women with a CD4 immune cell count of 200-500 cells/mm3 are given a combination of three ARVs to prevent transmission. This treatment should start in their last trimester of pregnancy, continuing through birth and six months of breastfeeding. This was shown to reduce the risk of transmitting HIV to the baby and improved survival compared with babies of mothers with HIV who are given the current WHO-recommended short-course ARV regimen in late pregnancy and around the time of delivery [47]. These findings suggest that a regimen combining triple ARV is most effective for preventing transmission of HIV from mothers to babies. The risk of adverse events to both mother and baby appears low in the short-term but the optimal antiretroviral combination and the optimal time to initiate this to maximize prevention efficacy without compromising the health of either mother or baby remains unclear.

\section{Immediate essential newborn care Thermal care for preterm babies and/or low birth weight infants}

An optimal thermal environment is desirable for preterm infants. When an infant is challenged by cold, the baby attempts to conserve body heat by vasoconstriction and to maintain body temperature via thermogenesis by the metabolism of brown adipose tissue and an increase in oxygen consumption. The increase in energy expenditure may reduce weight gain [48]. A number of measures have been suggested to assist in the maintenance of body temperature for infants except the traditionally used incubators.

The intervention includes (1) barriers to heat loss applied to any part of the body of the preterm and/or low birth weight (LBW) infant within 10 minutes after birth in the delivery suite. These would consist of coverings such as transparent plastic wraps and bags made of low-density 
polyethylene (LDPE) or semi-permeable membranes such as opsite or Tegaderm and other additional swaddling materials or wraps (excluding delivery room blankets) such as the 'silver swaddler'; 2) External heat sources (non-routine) initiated within 10 minutes after birth in the delivery suite such as skin-to-skin care and heated/gel/ chemical mattresses. Plastic wraps or bags were found to be effective in reducing heat losses in infants $<28$ weeks' gestation (Weighted Mean Difference (WMD) $0.68^{\circ} \mathrm{C}$; $95 \%$ CI $0.45,0.91)$, but not in infants between 28 to 31 week's gestation. Plastic caps were effective in reducing heat losses in infants <29 weeks' gestation (MD $0.80^{\circ} \mathrm{C}$; $95 \% \mathrm{CI}$ $0.41,1.19$ ). There was insufficient evidence to suggest that either plastic wraps or plastic caps reduce the risk of death within hospital stay. On the other hand, skin-to-skin care was shown to be effective in reducing the risk of hypothermia when compared to conventional incubator care for infants (RR 0.09; 95\% CI 0.01, 0.64). The transwarmer mattress reduced the incidence of hypothermia on admission to NICU in very LBW infants (RR 0.30; 95\% CI 0.11 , 0.83 ) [49]. These findings suggest that any intervention other than primary care designed for prevention of hypothermia, and applied within 10 minutes after birth in the delivery suite, may be beneficial in practice including plastic wraps and bags, skin-to-skin contact, and transwarmer mattresses. These interventions keep infants warmer and decreased the incidence of hypothermia. To prevent the morbidity and mortality in preterm infants due to hypothermia, consideration should be given to using these interventions in the delivery suite.

\section{Advise on support of early initiation of breastfeeding}

The benefits of breastfeeding on mother and newborn have been well documented, and the WHO recommends that all mothers initiate breastfeeding within the first hour after giving birth [50,51]. Timing of start of breastfeeding is very important, with studies suggesting much greater benefits of early versus late feeding. Early initiation of breastfeeding is defined as feeding within the first day after delivery while late (delayed) initiation of breast feeding is when it starts after the first day of delivery.

A review of interventions to promote breastfeeding showed increased rates of initiation of breastfeeding (RR 1.53; 95\% CI: 1.25, 1.87) [52]; another review also showed similar results (RR 1.45; 95\% CI: 1.14, 1.84) [53]. Community-based intervention packages for reducing maternal and neonatal morbidity and mortality also showed an increase in rates of breastfeeding (RR 1.94; 95\% CI: 1.56, 2.42) [54]. Early versus late initiation of breastfeeding was found to be associated with decreased neonatal mortality (RR 0.52; 95\% CI: $0.27,0.98)$ while the effect of breastfeeding when compared to no breastfeeding also decreased neonatal mortality (RR 0.30; 95\% CI: 0.17, 0.53) [55]. Another review showed that early breastfeeding initiation was associated with lower risks of all-cause neonatal mortality among all live births
(RR 0.56; 95\% CI: 0.40, 0.79) and among LBW babies (RR 0.58; 95\% CI: 0.43, 0.78), as well as infection-related neonatal mortality (RR 0.55; 95\% CI: 0.36, 0.84) [56]. When evaluating antenatal breastfeeding education, a formal breastfeeding education workshop vs. routine care increased the initiation rate of breastfeeding (RR 1.19; 95\% CI: $0.97,1.45)$; peer counseling versus routine care showed higher increments in the initiation rates of breastfeeding (RR 1.82; 95\% CI: 1.13, 2.93). Less significant increases were observed at 3 months and 6 months after the education workshop [57]. Another review by Imdad et al. 2011 compared breastfed versus non breastfed infants and showed a significant $70 \%$ reduction in the risk of neonatal mortality. It also showed that early initiation of breastfeeding versus late reduced neonatal mortality significantly by $48 \%$.

\section{Promotion and provision of hygienic cord and skin care}

An umbilical cord infection may be clinically obvious while sometime tracking of bacteria along the umbilical vessels might not be apparent but can lead to septicemia, or other focal infections such as septic arthritis as a result of blood-borne spread $[58,59]$. In such cases, affected babies may also present with fever, lethargy or poor feeding. Soon after a normal delivery, the skin of the newborn baby including the umbilical stump is colonized mainly by nonpathogenic bacteria such as coagulase negative Staphylococci and Diphtheria bacilli. Pathogenic bacteria such as Coliforms and Streptococci may also be present on the skin and can track up the umbilical stump causing infection. It is therefore essential to keep the cord clean.

Antiseptic versus dry cord care/placebo decreased cord infection rates (RR 0.53; 95\% CI: 0.25, 1.13); alcohol showed lower cord infection rates as well (RR 0.63; 95\% CI: 0.19, 2.06]; triple dye also lowered infection (RR 0.68; 95\% CI: 0.13, 3.49]; salicylic sugar powder showed significant reductions in infection rates (RR 0.21; 95\% CI: $0.01,4.38)$. Antiseptics that were aqueous based and alcohol based were effective for cord separation: (WMD -4.76; 95\% CI: -5.34, -4.19) and (WMD -10.05; 95\% CI: $-10.72,-9.38$ ) respectively, when compared with powder based antiseptics [60]. A single study [61] evaluating the effect of chlorhexidine cleansing of the newborn skin showed reduced rate of bacterial colonization by Staphylococcus aureus (RR 0.65; 95\%CI: 0.55, 0.77), Streptococci (RR 0.53; 95\%CI: 0.27, 1.04); and E. Coli infections [61]. Chlorhexidine versus no treatment in cleaning skin of LBW newborn decreased neonatal mortality (RR 0.72; 95\%CI: $0.55,0.95)$ [61]. Another review also indicated that the use of chlorhexidine led to a $23 \%$ reduction in all-cause neonatal mortality in the intervention group compared to control (RR 0.77; $95 \%$ CI: 0.63, 0.94) [62]. A study conducted in Nepal found that there was a $28 \%$ reduction in mortality among LBW infants when chlorhexidine was used to clean the skin [63]. 


\section{Neonatal resuscitation with bag and mask for babies who do not breathe at birth}

At birth, the lungs of newborn babies are filled with fluid. This fluid must be cleared and replaced with air after birth. While most babies manage by themselves, one in every 20 to 30 newborns receives resuscitation at birth, mostly for absent or ineffective breathing. Effective ventilation is the key to successful neonatal resuscitation. Positive pressure ventilation is initiated with manual ventilation devices which may or not deliver positive end-expiratory pressure (PEEP).

A review by OO'Donnell et al. found insufficient evidence to determine the efficacy and safety of PEEP during positive pressure ventilation at neonatal resuscitation [64]. Ventilation is frequently initiated with a manual resuscitation bag and face-mask (BMV) followed by endotracheal intubation (ETT) if depression continues. These techniques may be difficult to perform successfully resulting in prolonged resuscitation or severe neonatal depression. The laryngeal mask airway (LMA) may achieve initial ventilation and successful resuscitation faster than a bag-mask device or endotracheal intubation. The review by Grein et al. found no difference between the LMA and ETT with the exception of a clinically insignificant difference in time to complete insertion of the device favoring the ETT [65]. Recent American Academy of Pediatrics guidelines reported that LMA that fit over the laryngeal inlet have been shown to be effective for ventilating newborns weighing more than $2000 \mathrm{~g}$. A laryngeal mask should be considered during resuscitation if facemask ventilation is unsuccessful and tracheal intubation is unsuccessful or not feasible. While, endotracheal intubation may be indicated for initial endotracheal suctioning of non-vigorous meconium-stained newborns, if bag-mask ventilation is ineffective or prolonged, when chest compressions are performed or for special resuscitation circumstances, such as congenital diaphragmatic hernia or extremely low birth weight [66]. Despite formal guidelines for the use of epinephrine in neonatal resuscitation, the evidence for these recommendations has not yet been rigorously scrutinized. A review evaluating the effectiveness of epinephrine in the context of apparent stillbirth or extreme bradycardia found no studies meeting the criteria for inclusion [67]. A meta-analysis of three facility-based studies found decreased rates of intrapartum related neonatal deaths with resuscitation training (RR 0.70, 95\%CI 0.59, 0.84). The evidence for basic resuscitation in community settings showed significant reductions in all-cause neonatal or perinatal mortality, ranging from $25-61 \%$, and asphyxia specific mortality, ranging from $61-70 \%$ [68]. There is no existing evidence from randomized, controlled trials to support or refute the administration of epinephrine to reduce mortality and morbidity in apparently stillborn or extremely bradycardic newborn infant. Similarly, no randomized, controlled trial exists to address the issues of optimum dosage and route of administration of epinephrine. On the other hand, facility based resuscitation training have reported reductions in intrapartum related neonatal mortality and community based resuscitation training found reduction in all cause and asphyxia related neonatal mortality.

\section{Neonatal infection management \\ Presumptive antibiotic therapy for the newborn at risk of bacterial infection}

Early onset of bacterial infection is an important cause of morbidity and mortality in newborn infants. Various factors that increase the risk of neonatal infection have been identified. It is unclear whether asymptomatic newborn infants born to mothers with one or more of these risk factors should receive antibiotics prophylactically rather than selectively if only clinical or microbiological evidence of sepsis emerges.

A review [69] identified two small trials undertaken in the 1970s. Both trials had methodological weaknesses and there was no evidence of an effect on any on these outcomes. Therefore, a large randomized controlled trial is needed in asymptomatic term infants born to mothers with risk factors for infection in their babies, which compares the effect of prophylactic versus selective antibiotics on morbidity, mortality and costs.

\section{Case management of neonatal sepsis, meningitis and pneumonia}

Neonatal sepsis is defined as a clinical syndrome of bacteremia with systemic signs and symptoms of infection in the first 4 weeks of life. Infection remains a major cause of illness and death in the neonatal period [70,71]. Treatment is initially with ampicillin plus either gentamicin or cefotaxime, narrowed to organism-specific drugs as soon as possible. Neonatal pneumonia is lung infection in a neonate and its signs may be limited to respiratory distress or progress to shock and death. Diagnosis is by clinical and laboratory evaluation for sepsis. Both pneumonia and neonatal sepsis can be treated in hospital or community setting.

For early onset neonatal sepsis ( $<48$ hours), monotherapy versus combination therapy showed a decrease in mmortality in the first 28 days of life (RR 0.75; $95 \%$ CI: 0.19, 2.90) [72]. For late onset neonatal sepsis, Beta-lactam antibiotics versus a combination of beta-lactam plus aminoglycoside decreased mortality prior to discharge (RR 0.17; 95\% CI: $0.01,3.23)$; and also a reduction in treatment failure (RR 0.17; 95 \% CI: 0.01, 3.23) [73]. The case-management for pneumonia showed reduction in total mortality by $27 \%$ (95\% CI 18,35\%) and pneumonia specific mortality by $42 \%$ (22-57\%) [74]. Similar findings were reported in the relatively recent review which reported $25 \%$ reduction in 
all-cause neonatal mortality (RR 0.75 95\% CI 0.64, 0.89) and $42 \%$ reductions in pneumonia-specific mortality (RR 0.58 95\% CI 0.41, 0.82) [75]. However, two studies evaluating community-based neonatal care packages including injectable antibiotics found $44 \%$ and $34 \%$ reductions in neonatal mortality (RR 0.56, 95\% CI 0.41,0.77; RR $0.66,95 \%$ CI $0.47,0.93$ respectively), but the interpretation of these results is complicated by co-interventions [75]. Similar findings were reported by Bhutta et al. in a review on community-based management of neonatal sepsis; the review reported $27 \%$ reduction in all-cause neonatal mortality (95\% CI: $18,35 \%$ ), and $42 \%$ reduction in pneumonia specific mortality (95\% CI: 22,57\%) [76]. On the basis of available evidence it can be concluded that antibiotics have a clear role in reducing neonatal mortality in LMICs and can be effectively administered at homes via trained health workers as well as for hospital-based management of neonatal sepsis.

\section{Interventions for small and ill babies Kangaroo mother care for preterm babies}

Preterm birth (before 37 completed weeks of gestation) is the most important direct cause of neonatal mortality and it accounts for an estimated $27 \%$ of the four million neonatal deaths every year $[4,77]$. In the early 1970 s, motivated by problems arising from shortage of incubators and also the impact of mother and newborn separation, Colombian paediatrician Edgar Ray developed a technologically simple method later named Kangaroo Mother Care (KMC). Acceptance of the KMC method is increasingly widespread and it is considered equivalent to conventional neonatal care for stable preterm infants and more parent and baby friendly [78].

KMC led to a decrease in neonatal mortality (RR 0.49; 95\% CI: 0.31, 0.77) [79] (RR 0.68; 95\% CI: 0.48, 0.96) [80], as well as severe morbidity (RR $0.34 ; 95 \% \mathrm{CI}: 0.18,0.65$ ) [79], (RR 0.57; 95\% CI: 0.40, 0.80) [80]. This evidence is sufficient to recommend the routine use of KMC in facilities for babies $<2000 \mathrm{~g}$ at birth. The potential effect of KMC is greatest in LMICs, where other options for care of preterm babies remain limited with few neonatal care facilities, mainly in distant referral hospitals and those that are often understaffed and ill-equipped.

\section{Extra support for feeding the small and preterm baby}

The composition of weight gained by the fetus varies with gestational age. About $80 \%$ of all weight gained between 24 and 28 weeks of gestation is water, but this proportion decreases to about $60 \%$ between 36 and 40 [81] weeks. It is usual clinical practice therefore to provide infants weighing $<1500 \mathrm{~g}$ with about $80 \mathrm{ml} / \mathrm{kg}$ for the first day of life and increase fluids by about $10-15 \mathrm{ml} / \mathrm{kg} /$ day to a maximum of $160 \mathrm{ml} / \mathrm{kg} /$ day by the end of the first week of life. Similarly, LBW infants $>1500$ g are usually given about $60 \mathrm{ml} / \mathrm{kg}$ for the first day of life and the fluid intake is increased by about $15-20 \mathrm{ml} / \mathrm{kg} /$ day to a maximum of $160 \mathrm{ml} / \mathrm{kg} /$ day by the end of the first week of life [81-83].

A meta-analysis of studies comparing restricted with liberal fluid regimens demonstrated that restricted fluid regimens were found to be associated with a lower risk of patent ductus arteriosus (RR 0.40; 95\% CI: 0.26, 0.63), necrotizing enterocolitis (RR 0.30; 95\% CI: 0.13, 0.71), and death (RR 0.52; 95\% CI: 0.28, 0.96) [84]. LBW babies, who are often due to preterm births, account for significant complications and poor health during infancy. According to studies included in this review, breastfeeding is the best option for LBW infants, unless unavailable, whereby donor human milk is the next best choice. Supplementation of breast milk with calcium and phosphorus is also recommended for babies with birth weight less than $1500 \mathrm{~g}$. Nutritional supplements, which are given separately from breast milk, available as single vitamin preparations (vitamin A, vitamin D, vitamin $\mathrm{K}$ ) or single mineral preparations (iron, zinc, calcium and phosphorus) are also beneficial (Paper 4, vitamin A supplementation in children).

\section{Prophylactic use of synthetic surfactant}

Pulmonary surfactant is a substance produced by the lung alveoli and prevents the lungs from collapsing during expiration by decreasing surface tension. It is noted that babies who are born before 30 weeks, approximately $60 \%$ of them will develop respiratory distress syndrome (RDS) because lung maturity is directly proportional to the level of surfactant that is present in the newborn [85].

A review evaluated outcomes in infants given synthetic surfactant (pre-ventilatory or post-ventilatory) compared with control treatment which consisted of intratracheal administration of normal saline or air placebo. The different types of synthetic surfactant used in these trials were DPPC plus high density lipoprotein, powdered DPPC and phosphatidylglycerol and DPPC plus phosphatidylglycerol in saline. Studies also compared surfactant [86] given as either multiple or single doses to infants who were either premature ( $<30$ weeks gestation or $<1250 \mathrm{~g})$, at risk of respiratory distress syndrome or premature infants with established respiratory distress syndrome requiring assisted ventilation. Prophylactic synthetic surfactant versus normal saline or placebo decreased rates of pneumothorax (RR 0.67; 95\% CI: 0.50, 0.90); neonatal mortality (RR 0.70; 95\% CI: 0.58, 0.85); pulmonary interstitial emphysema (RR $0.68 ; 95 \%$ CI: $0.50,0.93$ ); and mortality at 1 year (RR 0.83; 95\% CI: 0.70, 0.98) [86]. Multiple versus single dose of surfactant decreased rates of pneumothorax (RR 0.70; 95\%CI: 0.52, 0.94); pulmonary interstitial emphysema (RR 0.62; 95\% CI: 0.54, 0.71), mortality (RR 0.59; 95\% CI: $0.44,0.78$ ), and necrotizing enterocolitis (RR 0.18 ; 95\% CI: $0.07,0.44)$. No significant changes were seen in rates of patent ductus arteriosus or intraventricular haemorrhage 
[86]. Infants who underwent prophylactic administration of synthetic surfactant had a decreased risk of pneumothorax, pulmonary interstitial emphysema and neonatal mortality. Also infants who were given synthetic surfactant showed an increased risk of developing patent ductus arteriosus and pulmonary haemorrhage. Rresults also show that multiple doses of surfactant as prevention or treatment resulted in a statistical significance reduction in the incidence of pneumothorax, mortality and necrotizing enterocolitis.

Therapeutic surfactant use for respiratory distress syndrome Even though surfactant therapy has shown to improve outcomes for premature infants with RDS it is important to note that this therapy should not be used as an alternative to prolonging premature deliveries in order to increase lung maturity, or giving mothers antenatal corticosteroids with the aim to prevent RDS from developing [87-91].

A meta-analysis supports decrease in the risk of pneumothorax (RR 0.64, 95\% CI 0.55,0.76), pulmonary interstitial emphysema (RR $0.62,95 \%$ CI $0.54,0.71$ ), patent ductus arteriosus (RR 0.90, 95\% CI 0.84, 0.97), intraventricular haemorrhage ( $\mathrm{RR}$ risk $0.88,95 \%$ CI $0.77,0.99$ ), broncho-pulmonary dysplasia (RR 0.75 , 95\% CI 0.61 , 0.92 ), neonatal mortality (RR $0.73,95 \%$ CI $0.61,0.88$ ), broncho-pulmonary dysplasia or death at 28 days (RR 0.73 , 95\% CI $0.65,0.83)$, mortality prior to hospital discharge (RR $0.79,95 \%$ CI $0.68,0.92$ ) and mortality during the first year of life (RR $0.80,95 \%$ CI $0.69,0.94$ ). Treatment with synthetic surfactant increases the risk of apnea of prematurity (RR 1.20, 95\% CI 1.09, 1.31) [92]. Early versus delayed selective surfactant treatment decreased chronic lung disease rates (typical RR 0.69; 95\% CI: 0.55, 0.86; typical Risk Difference (RD) -0.04; 95\% CI: $-0.06,-0.01)$; acute lung injury including a decreased risk of pneumothorax (typical RR 0.69; 95\% CI: 0.59, 0.82); pulmonary interstitial emphysema (typical RR 0.60; 95\% CI: 0.41, 0.89) and broncho-pulmonary dysplasia (BPD) or death at 28 days was also evident (typical RR 0.94; 95\% CI: 0.88, 1.00) [93]. Existing evidence shows that giving synthetic surfactant to infants with established RDS improves clinical outcome. Infants who are treated with synthetic surfactant were found to have a decreased risk of pneumothorax, pulmonary interstitial emphysema, intraventricular haemorrhage, and Broncho pulmonary dysplasia. There was also a reduction in the incidence of neonatal mortality, mortality prior to hospital discharge and at 1 year of age. Infants who received synthetic surfactant treatment for established RDS also had an increased risk of apnea of prematurity. All results that are mentioned in this section reached statistical significance upon analysis. The results in the review of Soll 2009 et al. were for both prevention and treatment of respiratory distress syndrome. They showed that multiple doses of surfactant resulted in a decreased risk pneumothorax, mortality and necrotizing enterocolitis.
Continuous positive airway pressure (CPAP) to manage preterm babies with respiratory distress syndrome

Apnea of prematurity, which is commonly seen in infants who are born before 34 weeks of gestation, is defined as a pause in breathing for greater than twenty seconds or an apneic event that is less than twenty seconds but is associated with bradycardia and/or cyanosis $[94,95]$. Continuous positive airway pressure (CPAP), has shown to be effective without long term effects; however, this has not been fully observed. Another treatment option is with ventilation (NIPPV, nasal intermittent positive pressure ventilation) which is delivered through the nasal route, and this also has seen to be effective in preterm infants whose apnea is frequent and severe [96]. As with the other treatment options there are some drawbacks with the use of NIPPV also, it has been noted that providing ventilation via nasal prongs is associated with an increased risk of gastrointestinal perforation [97].

A meta-analysis demonstrates that high frequency positive pressure ventilation (HFPPV) compared to conventional ventilation (CMV) was associated with a reduction in the risk of air leak (RR 0.69, 95\% CI 0.51, 0.93). Assist control ventilation (ACV) or synchronized intermittent mandatory ventilation (SIMV) compared to CMV was associated with a shorter duration of ventilation (WMD -34.8 hours, 95\% CI -62.1, -7.4). ACV compared to SIMV was associated with a trend to a shorter duration of weaning (WMD -42.4 hours, 95\% CI -94.4, 9.6). Neither HFPPV nor triggered ventilation was associated with a significant reduction in the incidence of BPD [98]. NIPPV vs. NCPAP decreased rates of failure of therapy (intubation) (RR 0.30; 95\%CI: 0.01, 6.84), rate of apnea (events/hr) (MD -0.10 events/hr; 95\%CI: -0.53, 0.33) and change in rate of apnea (events/hr) (MD -1.19 events/hr; 95\%CI: $-2.31,-0.07)$. NIPPV when compared to NCPAP may be a useful method in preterm infants with apnea [99]. Continuous distending pressure (CDP), on the other hand, is found to be associated with a lower rate of failed treatment (death or use of assisted ventilation) (RR 0.65 95\% CI 0.52, 0.81), overall mortality (RR 0.52 95\% CI $0.32,0.87)$, and mortality in infants with birth weights above $1500 \mathrm{~g}$ (RR 0.24 95\% CI 0.07, 0.84). The use of CDP is associated with an increased rate of pneumothorax (RR 2.64 95\% CI 1.39, 5.04) [100]. A review by Greenough et al. [98] shows that there are more benefits in treating neonates with HFPPV or triggered ventilation compared to conventional ventilation. There was a reduction in both air leaks and duration of ventilation. Even though benefits were documented in this review, we encourage that more trials are done in order to determine the effectiveness of ventilation, along with other benefits or long term risk associated with these methods. 


\section{Management of newborns with jaundice}

Extremely high levels of bilirubin (severe jaundice) can lead to brain damage. Severe jaundice in newborns can occur as a result of a variety of causes including rhesus hemolytic disease, $\mathrm{ABO}$ incompatibility, atypical antibodies etc. Removal of blood from the affected infant and replacing with fresh blood from the blood bank (exchange transfusion) is used as a treatment for severe jaundice in newborn infants.

Phototherapy is used to treat newborn infants with hyperbilirubinaemia. Fibreoptic phototherapy is a new mode of phototherapy which is reported to lower serum bilirubin (SBR) while minimizing disruption of normal infant care. Fibreoptic phototherapy was found to be more effective at lowering SBR (serum bilirubin) than no treatment but less effective than conventional phototherapy. Fibreoptic phototherapy was equally as effective as conventional phototherapy in preterm infants and when two fibreoptic devices were used simultaneously (change in SBR after 24 hours of treatment: (WMD 1.7\%; 95\%CI: $-2.65,6.05)$ and change in SBR per day over whole treatment period: (WMD 2.82\%; 95\%CI: -1.84, 7.48 respectively). A combination of fibreoptic and conventional phototherapy was more effective than conventional phototherapy alone (duration of phototherapy): (WMD $-12.51 \mathrm{hr}$; $95 \% \mathrm{CI}$ : $-16.00,-9.02$, meta-analysis affected by heterogeneity) [101].

Fibreoptic phototherapy has a place in the management of neonatal hyperbilirubinaemia. It is probably a safe alternative to conventional phototherapy in term infants with physiological jaundice.

Double volume exchange transfusion is commonly used in newborns with severe jaundice in order to prevent kernicterus and other toxicity related to hyperbilirubinemia. A single trial fulfilling the criteria for inclusion identified 20 full term babies requiring exchange transfusion for hemolytic jaundice due to ABO incompatibility. These infants were randomly allocated to receive single or double volume exchange transfusion. Total bilirubin levels immediately after exchange transfusion were not significantly different in either group. There was insufficient evidence to support or refute the use of single volume exchange transfusion as opposed to double volume exchange transfusion in jaundiced newborns [102].

\section{Discussion}

This paper summarized all the essential childbirth and postnatal interventions for improved maternal and newborn health. The interventions were preventive and therapeutic aimed at preventing illnesses and improve survival of mothers and babies. The importance of these interventions has been addressed in previous publications [103-106]. However this review further underscored their standing by collating the existing evidence to assist health professionals and policy makers to reduce the existing burden of maternal and neonatal morbidity and mortality.

Among the childbirth interventions, the review highlighted the role of injecting oxytocin immediately after childbirth for the prevention and management of postpartum hemorrhage, which is lethal and is responsible for large number of maternal deaths if unattended. Similarly, practicing good hygiene and recognition of early signs of infection after childbirth can be instrumental in saving lives. Detection and management of pre-eclampsia and use of magnesium sulphate can lower a woman's risk of developing eclampsia and other life-threatening complications. For postnatal interventions, care of the neonate and mother in the hours following the delivery is vital and must be adequate to prevent the high risk of mortality and morbidity associated with it. The benefits of breastfeeding have been well documented; however the timing of start of breastfeeding is very important, with studies suggesting much greater benefits of early vs. late feeding [56]. Hygienic care of cord and skin of the baby after delivery for lowering the risk of infections have the potential to reduce neonatal deaths. Neonatal resuscitation is vital for preventing neonatal deaths due to birth asphyxia. Babies with respiratory problems should be assessed and administered surfactant or other ventilatory assistance such as CPAP immediately. Babies with LBW are advised to receive thermal care, as well as KMC along with appropriate extra support for feeding. Childbirth and postnatal care should not be limited to a definite period whereby only the current health status of both mother and child are addressed but should also link the mother to family-planning services and the baby to child health care which will cater to the future needs of both child and mother [107]. The focus of delivering effective postnatal care must be on the timely delivery of intervention packages, i.e. on the first day after birth.

Childbirth and postnatal care faces many challenges in LMICs whereby establishing contact between the pregnant mother, postpartum mother, or neonate is difficult since home births and seclusion may be a community practice or tradition. However, the importance of community based delivery strategies to increase access to needed care is paramount to bringing about a positive change in the developing countries. Although not all the interventions discussed in this paper can be delivered in community, training community midwives and detailing proper linkages with local health facilities is very vital. Referrals from community to health facilities for interventions such as, management of postpartum hemorrhage and cesarean sections is very critical. Therefore, training midwives and follow-ups through home visits may assist in increasing the coverage and improving the quality of home-based postnatal care services for mothers and newborns. This goal can be achieved through increased utilization of basic 
postnatal services by mothers and newborns, increased identification and referral of post-partum women and newborns with health problems to health care facilities, and provision of quality home based postnatal care for mothers and newborns [108].

This paper is a comprehensive and through summary of essential childbirth and postnatal interventions for health care practitioners and decision makers who can integrate these interventions into health system for improved maternal and child health. If implemented properly to target a wider audience, keeping in mind the barriers to implementation, then major progress may be made in meeting the MDG's and higher maternal and neonatal maternal mortality would be ceased. The strength of this paper is that it included and summarized evidence from all the recent Cochrane and non-Cochrane reviews on childbirth and postnatal interventions for mothers and newborns. However, at times the quality of all included studies within the review could not be ensured which limited the quality of the data obtained.

\section{Conclusion}

Maternal and newborn health exists in a synergistic relation. Most maternal deaths are avoidable provided timely and adequate delivery of health-care solutions to prevent or manage complications. An access to antenatal care in pregnancy, skilled care during childbirth, and care and support in the weeks after childbirth should be provided to all women. The review discussed all childbirth and postnatal interventions which have an impact on reducing maternal, neonatal mortality and which are suitable for delivery in LMICs. The implementations of discussed interventions promise a much needed improvement is maternal and neonatal outcomes around the world. However, some of these interventions must be prioritized over others depending on the clinical indications and keeping in view the limited resources in developing countries. Timely provision of these interventions holds unparalleled significance, particularly those that are delivered during and immediately after childbirth, in places where majority of the births occur, at home.

\section{Peer review}

The reviewer reports for this article can be found in Additional File 1.

\section{Additional material}

Additional file 1: Peer review reports.

\section{Competing interests}

We do not have any financial or non-financial competing interests for this review.

\section{Acknowledgment}

The publication of these papers and supplement was supported by an unrestricted grant from The Partnership for Maternal, Newborn and Child Health.

\section{Declarations}

This article has been published as part of Reproductive Health Volume 11 Supplement 1, 2014: Essential intervention for maternal, newborn and child health. The full contents of the supplement are available online at www. reproductive-health-journal.com/supplements/11/S1. Publication charges for this collection were funded by the Partnership for Maternal, Newborn \& Child Health (PMNCH)

Published: 21 August 2014

\section{References}

1. WHO: Maternal mortality [http://www.who.int/mediacentre/factsheets/ fs348/en/]. 2012

2. Zupan J, Aahman E: Perinatal mortality for the year 2000: estimates developed by WHO. Geneva: World Health Organization 2005.

3. Lozano R, Wang H, Foreman KJ, Rajaratnam JK, Naghavi M, Marcus JR, Dwyer-Lindgren L, Lofgren KT, Phillips D, Atkinson C: Progress towards Millennium Development Goals 4 and 5 on maternal and child mortality: an updated systematic analysis. Lancet 2011, 378(9797):1139-1165.

4. Lawn JE, Cousens S, Zupan J: 4 million neonatal deaths: when? Where? Why? Lancet 2005, 365(9462):891-900.

5. World Health Organization M Newborn Health/Safe Motherhood U: Postpartum Care of the Mother and Newborn: A Practical Guide: Report of a Technical Working Group: Stationery Office. 1998.

6. Sines E, Syed U, Wall S, Worley H: Postnatal care: A critical opportunity to save mothers and newborns. Policy Perspectives on Newborn Health 2007.

7. Lauer JA, Betran AP, Barros AJD, de Onis M: Deaths and years of life lost due to suboptimal breast-feeding among children in the developing world: a global ecological risk assessment. Public Health Nutr 2006, 9(06):673-685.

8. Lassi ZS, Salam RA, Dai JK, Bhutta ZA: Essential interventions for maternal, newborn and child health: background and methodology. Reproductive Health 2014, 11(Suppl 1):S1.

9. Klaus M, Kennell J, Klaus P: The doula book: how a trained labor companion can help you have a shorter, easier and healthier birth. Cambridge, MA: Perseus Books; 22002.

10. Hodnett ED, Gates S, Hofmeyr GJ, Sakala C: Continuous support for women during childbirth. Cochrane Database Syst Rev 2013, 7(7):CD003766.

11. Gibbs RS: Clinical risk factors for puerperal infection. Obstet Gynecol 1980, 55(3):178S-183S

12. Henderson $E$, Love EJ: Incidence of hospital-acquired infections associated with caesarean section. J Hosp Infect 1995, 29(4):245-255.

13. Boggess KA, Watts DH, Hillier SL, Krohn MA, Benedetti TJ, Eschenbach DA: Bacteremia shortly after placental separation during cesarean delivery. Obstet Gynecol 1996, 87(5, Part 1):779-784.

14. Leigh DA, Emmanuel FXS, Sedgwick J, Dean R: Post-operative urinary tract infection and wound infection in women undergoing caesarean section: a comparison of two study periods in 1985 and 1987. J Hosp Infect 1990, 15(2):107-116.

15. MacLean A: Puerperal pyrexia. In Clinical Infection in Obstetrics and Gynecology. Oxford: Blackwell ScientificPublications MacLeanAB 1990, 195-209.

16. Smaill FM, Gyte GM: Antibiotic prophylaxis versus no prophylaxis for preventing infection after cesarean section. Cochrane Database Syst Rev 2010, 1(1):CD007482.

17. Lewis G: Whymothers die 2000-2002 - Sixth report of the confidential enquires intomaternal deaths. : 2004; United Kingdom London: RCOG Press; 2004.

18. World Health Organization: Vaginal bleeding after childbirth. Managing complications in pregnancy and childbirth: a guide for midwives and doctors. Geneva: WHO; 2000, S25-S34.

19. Prendiville WJP, Elbourne D, McDonald SJ: Active versus expectant management in the third stage of labour (Review). Cochrane Database Syst Rev 2000, 3(3):CD000007.

20. Gulmezoglu AM, Lumbiganon $P$, Landoulsi $S$, Widmer M, Abdel-Aleem $H$, Festin M, Carroli G, Qureshi Z, Souza JP, Bergel E: Active management of 
the third stage of labour with and without controlled cord traction: a randomised, controlled, non-inferiority trial. Lancet 2012, 379(9827):1721-1727.

21. Cotter AM, Ness A, Tolosa JE: Prophylactic oxytocin for the third stage of labour. Cochrane Database Syst Rev 2001, 4(4):CD001808.

22. Soltani $H$, Hutchon DR, Poulose TA: Timing of prophylactic uterotonics for the third stage of labour after vaginal birth. Cochrane Database Syst Rev 2010, 8(8):CD006173.

23. WHO: WHO recommendations for the prevention and treatment of postpartum haemorrhage. Geneva, Switzerland: World Health Organisation; 2012.

24. Begley CM, Gyte GM, Devane D, McGuire W, Weeks A: Active versus expectant management for women in the third stage of labour. Cochrane Database Syst Rev 2011, 11(11):CD007412.

25. McDonald S, Abbott JM, Higgins SP: Prophylactic ergometrine-oxytocin versus oxytocin for the third stage of labour. Cochrane Database Syst Rev 2004, 1(1):CD000201.

26. McDonald SJ, Middleton P, Dowswell T, Morris P: Effect of timing of umbilical cord clamping of term infants on maternal and neonatal outcomes. Cochrane Database Syst Rev 2013, 7(7):CD004074.

27. Pena-Marti G, Comunian-Carrasco G: Fundal pressure versus controlled cord traction as part of the active management of the third stage of labour. Cochrane Database Syst Rev 2007, 4(4):CD005462.

28. Olesen AW, Westergaard JG, Olsen J: Perinatal and maternal complications related to postterm delivery: a national register-based study, 1978-1993. Am J Obstet Gynecol 2003, 189(1):222-227.

29. Hilder L, Costeloe K, Thilaganathan B: Prolonged pregnancy: evaluating gestationâ€ Âspecific risks of fetal and infant mortality. BJOG 1998, 105(2):169-173.

30. Gulmezoglu AM, Crowther CA, Middleton P, Heatley E: Induction of labour for improving birth outcomes for women at or beyond term. Cochrane Database Syst Rev 2012, 6(6):CD004945.

31. Hussain AA, Yakoob MY, Imdad A, Bhutta ZA: Elective induction for pregnancies at or beyond 41 weeks of gestation and its impact on stillbirths: a systematic review with meta-analysis. BMC Public Health 2011, 11(Suppl 3):S5

32. Vayssiere C, Haumonte J-B, Chantry A, Coatleven F, Debord MP, Gomez C, Le Ray C, Lopez E, Salomon LJ, Senat MV: Prolonged and post-term pregnancies: guidelines for clinical practice from the French College of Gynecologists and Obstetricians (CNGOF). Eur J Obstet Gynecol Reprod Biol 2013, 169(1):10-16

33. Hofmeyr GJ, Abdel-Aleem $H$, Abdel-Aleem MA: Uterine massage for preventing postpartum haemorrhage. Cochrane Database Syst Rev 2013, 7(7):CD006431.

34. Tuncalp o, Hofmeyr GJ, Gulmezoglu AM: Prostaglandins for preventing postpartum haemorrhage. Cochrane Database Syst Rev 2012, 8(8): CD000494.

35. Mousa HA, Alfirevic Z: Treatment for primary postpartum haemorrhage. Cochrane Database Syst Rev 2007, 4(4):CD003249.

36. Glasier AF, Logan J, McGlew TJ: Who gives advice about postpartum contraception? Contraception 1996, 53(4):217-220.

37. Engin-Ustun Y, Ustun Y, Cetin F, Meydanh M, Kafkash A, Sezgin B: Effect of postpartum counseling on postpartum contraceptive use. Arch Gynecol Obstet 2007, 275(6):429-432.

38. International FH: Quick Reference Guide to Family Planning Research. Available from [http://www.fhi.org/en/RH/Programs/RtoP/underusedres. htm]. 2009, 48-51.

39. Lopez $L M$, Hiller $J E$, Grimes DA: Education for contraceptive use by women after childbirth. Cochrane Database Syst Rev 2010, 1(1):CD001863.

40. Atkinson LS, Baxley EG: Postpartum fatigue. Am Fam Physician 1994, 50(1):113-118.

41. Ekanem AD, Etuk SJ, Samson-Akpan U: The influence of cultural practice on puerperal anemia. Int J Gynaecol Obstet 1996, 55(2):169-170.

42. Harrison KA: Maternal mortality in developing countries. BJOG 1989, 96(1):1-3.

43. Kumar R, Sharma AK, Barik S, Kumar V: Maternal mortality inquiry in a rural community of north India. Int J Gynaecol Obstet 1989, 29(4):313-319.

44. World Health Organization: Reduction of maternal mortality. A joint WHO/UNFPA/UNICEF/World Bank statement. Geneva; 1999.

45. Dodd J, Dare MR, Middleton P: Treatment for women with postpartum iron deficiency anaemia. Cochrane Database Syst Rev 2004, 4(4):CD004222.
46. French LM, Smaill FM: Antibiotic regimens for endometritis after delivery. Cochrane Database Syst Rev 2004, 4(4).

47. De Vincenzi I: Triple-antiretroviral (ARV) prophylaxis during pregnancy and breastfeeding compared to short-ARV prophylaxis to prevent mother-to-child transmission of HIV-1 (MTCT): the Kesho Bora randomized controlled clinical trial in five sites in Burkina Faso, Kenya. 5th International AIDS Society Conference on HIV Pathogenesis, Treatment and Prevention, Cape Town, 19-22 July 2009: 20092009.

48. Glass L, Silverman WA, Sinclair JC: Relationship of thermal environment and caloric intake to growth and resting metabolism in the late neonatal period. Neonatology 1969, 14(5-6):324-340.

49. McCall EM, Alderdice F, Halliday HL, Jenkins JG, Vohra S: Interventions to prevent hypothermia at birth in preterm and/or low birthweight infants. Cochrane Database Syst Rev 2010, 3(3):CD004210.

50. World Health Organization: Division of Child Health and Development. Indicators for Assessing Breastfeeding Practice [reprinted report of an informal meeting 11-12 June, 1991]. Geneva, Switzerland: World Health Organization; 1991

51. United Nations Children's Fund/World Health Organization: Baby friendly hospital initiative. Geneva, Switzerland: United Nations Children's Fund/ World Health Organization. 2005 [www.unicef.org/nutrition/index_24806. html].

52. Dyson L, McCormick F, Renfrew MJ: Interventions for promoting the initiation of breastfeeding. Cochrane Database Syst Rev 2005, 2(2):CD001688.

53. Lewin S, Munabi-Babigumira S, Glenton C, Daniels K, Bosch-Capblanch X, van Wyk BE, Odgaard-Jensen J, Johansen M, Aja GN, Zwarenstein M: Lay health workers in primary and community health care for maternal and child health and the management of infectious diseases. Cochrane Database Syst Rev 2010, 3(3):CD004015.

54. Lassi ZS, Haider BA, Bhutta ZA: Community-based intervention packages for reducing maternal and neonatal morbidity and mortality and improving neonatal outcomes. Cochrane Database Syst Rev 2010, 11(11):CD007754.

55. Imdad A, Yakoob MY, Bhutta ZA: Effect of breastfeeding promotion interventions on breastfeeding rates, with special focus on developing countries. BMC Public Health 2011, 11(Suppl 3):S24.

56. Debes AK, Kohli A, Walker N, Edmond K, Mullany LC: Time to initiation of breastfeeding and neonatal mortality and morbidity: a systematic review. BMC Public Health 2013, 13(3):1-14.

57. Lumbiganon P, Martis R, Laopaiboon M, Festin MR, Ho JJ, Hakimi M: Antenatal breastfeeding education for increasing breastfeeding duration. Cochrane Database Syst Rev 2011, 11(11):CD006425.

58. Cullen TS: Embryology, Anatomy and Diseases of the Umbilicus. Saunders 1916.

59. Forshall I: Septic umbilical arteritis. Arch Dis Child 1957, 32(161):25.

60. Zupan J, Garner P, Omari AA: Topical umbilical cord care at birth. Cochrane Database Syst Rev 2004, 3(3):CD001057.

61. Tielsch JM, Darmstadt GL, Mullany LC, Khatry SK, Katz J, LeClerq SC, Shrestha S, Adhikari R: Impact of newborn skin-cleansing with chlorhexidine on neonatal mortality in southern Nepal: a communitybased, cluster-randomized trial. Pediatr 2007, 119(2):e330-e340.

62. Imdad A, Mullany LC, Baqui AH, El Arifeen S, Tielsch JM, Khatry SK, Shah R, Cousens S, Black RE, Bhutta ZA: The effect of umbilical cord cleansing with chlorhexidine on omphalitis and neonatal mortality in community settings in developing countries: a meta-analysis. BMC Public Health 2013, 13(Suppl 3):S15.

63. Tielsch JM, Darmstadt GL, Mullany LC, Khatry SK, Katz J, LeClerq SC, Shrestha $S$, Adhikari R: Impact of newborn skin-cleansing with chlorhexidine on neonatal mortality in southern Nepal: a communitybased, cluster-randomized trial. Pediatrics 2007, 119(2):e330-e340.

64. O'Donnell C, Davis P, Morley C: Positive end-expiratory pressure for resuscitation of newborn infants at birth. Cochrane Database Syst Rev 2004, 3(3):CD004341

65. Grein AJ, Weiner GM: Laryngeal mask airway versus bag-mask ventilation or endotracheal intubation for neonatal resuscitation. Cochrane Database Syst Rev 2005, 2(2):CD003314

66. Kattwinkel J, Perlman JM, Aziz K, Colby C, Fairchild K, Gallagher J, Hazinski MF, Halamek LP, Kumar P, Little G: Part 15: neonatal resuscitation 2010 american heart association guidelines for cardiopulmonary resuscitation and emergency cardiovascular care. Circulation 2010, 122(18 suppl 3):S909-S919. 
67. Ziino AJA, Davies MW, Davis PG: Epinephrine for the resuscitation of apparently stillborn or extremely bradycardic newborn infants. Cochrane Database Syst Rev 2002, 3(3):CD003849.

68. Lee A, Cousens S, Wall A, Niemeyer S, Darmstadt G, Carlo W, Keenan W, Bhutta Z, Lawn J: Neonatal resuscitation and immediate newborn assessment and stimulation for the prevention of neonatal deaths: a systematic review, meta-analysis and Delphi estimation of mortality effect. BMC Public Health 2011, 11(Suppl 3):S12.

69. Ungerer RLS, Lincetto O, McGuire W, Saloojee H, Gulmezoglu AM: Prophylactic versus selective antibiotics for term newborn infants of mothers with risk factors for neonatal infection. Cochrane Database Syst Rev 2004, 4(4):CD003957

70. Freedman RM, Ingram DL, Gross I, Ehrenkranz RA, Warshaw JB, Baltimore RS: A half century of neonatal sepsis at Yale: 1928 to 1978. Am J Dis Child 1981, 135(2):140.

71. Gladstone IM, Ehrenkranz RA, Edberg SC, Baltimore RS: A ten-year review of neonatal sepsis and comparison with the previous fifty-year experience. Pediatr Infect Dis J 1990, 9(11):819-890.

72. Mtitimila El, Cooke RW: Antibiotic regimens for suspected early neonatal sepsis. Cochrane Database Syst Rev 2004, 4(4):CD004495.

73. Gordon A, Jeffery HE: Antibiotic regimens for suspected late onset sepsis in newborn infants. Cochrane Database Syst Rev 2005, 3(3):CD004501.

74. Sazawal S, Black RE: Effect of pneumonia case management on mortality in neonates, infants, and preschool children: a meta-analysis of community-based trials. Lancet Infect Dis 2003, 3(9):547-556.

75. Zaidi AKM, Ganatra HA, Syed S, Cousens S, Lee ACC, Black R, Bhutta ZA, Lawn JE: Effect of case management on neonatal mortality due to sepsis and pneumonia. BMC Public Health 2011, 11(Suppl 3):S13.

76. Bhutta ZA, Zaidi AKM, Thaver D, Humayun Q, Ali S, Darmstadt GL: Management of newborn infections in primary care settings: a review of the evidence and implications for policy? Pediatr Infect Dis J 2009, 28(1):S22-S30.

77. Lawn JE, Wilczynska-Ketende K, Cousens SN: Estimating the causes of 4 million neonatal deaths in the year 2000. int J Epidemiol 2006, 35(3):706-718.

78. Charpak N, Gabriel Ruiz J, Zupan J, Cattaneo A, Figueroa Z, Tessier R, Cristo M, Anderson G, Ludington S, Mendoza S: Kangaroo mother care: 25 years after. Acta Paediatr 2005, 94(5):514-522.

79. Lawn JE, Mwansa-Kambafwile J, Horta BL, Barros FC, Cousens S: Kangaroo mother care' to prevent neonatal deaths due to preterm birth complications. int J Epidemiol 2010, 39(suppl 1):i144-i154.

80. Conde-Agudelo A, Belizan JM, Diaz-Rossello JL: Kangaroo mother care to reduce morbidity and mortality in low birthweight infants. Cochrane Database Syst Rev 2011, 3(3):CD002771.

81. Fusch FJ: Water, sodium, potassium, and chloride. In Nutrition of the preterm infant: scientific basis and practical guide- lines.. 2 edition. Cincinnati, OH: Digital Educational Publishing;Tsang RC et al 2005:

82. Bell EFOW: Fluid and electrolyte management. In Neonatology: Pathophysiology of the Newborn.. 5 edition. Philadelphia Lippincott Williams and Wilkins;Avery GB, Fletcher MA, MacDonald MG 1999:345-361.

83. Fomon SJ, Haschke F, Ziegler EE, Nelson SE: Body composition of reference children from birth to age 10 years. Am J Clin Nutr 1982, 35(5):1169-1175.

84. Edmond K, Bahl R: Optimal feeding of low-birth-weight infants. Geneva: World Health Organization; 2006.

85. Jobe A: Pulmonary surfactant therapy. N Engl J Med 1993, 328:861-868.

86. Soll R, Ozek E: Multiple versus single doses of exogenous surfactant for the prevention or treatment of neonatal respiratory distress syndrome. Cochrane Database Syst Rev 2009, 1(1):CD000141.

87. Jobe A: Lung Development. In Neonatal-perinatal Medicine, Diseases of the Fetus and Infant. St Louis: Mosby Martin RJ, Fanaroff AA 1997, 1019-1040.

88. Fackler J, Arnold J, Nickols D, Rogers M: Acute Respiratory Distress Syndrome. In Textbook of Pediatric Intensive Care, Baltimore: Williams and Wilkins Rogers MC 1996, 197-225.

89. Gomella TL, Gleason BL: Hyalin Membrane Disease. Neonatology Appleton and Lange 1988, 89:381-385.

90. Honrubia D, Stark A: Respiratory Disorders. In Manuale of Neonatal Care. Philadelphia: Lippincott, Williams \& Wilkins Cloherty JP, Eichenwald EC, Strak AR 1997, 341-378.

91. Katz R: Function and Physiology of the Respiratory System. In Pediatric critical care. St Louis: Mosby Furhman BP, Zimmerman JJ 1992, 386-399.

92. Soll R: Synthetic surfactant for respiratory distress syndrome in preterm infants. Cochrane Database Syst Rev 1998, 3(3):CD001149.
93. Soll RF: Early versus delayed selective surfactant treatment for neonatal respiratory distress syndrome. Cochrane Database Syst Rev 2012, 11(11): CD001456.

94. Barrington K, Finer N: The natural history of the appearance of apnea of prematurity. Pediatr Res 1991, 29(4 Pt 1):372-375.

95. Nelson NM: Members of task force on prolonged apnea: reports of the task force on prolonged apnea of the American Academy of Pediatrics. Pediatr 1978, 61:651-652.

96. Ryan CA, Finer NN, Peters KL: Nasal intermittent positive-pressure ventilation offers no advantages over nasal continuous positive airway pressure in apnea of prematurity. Arch Pediatr Adolesc Med 1989, 143(10):1196.

97. Garland JS, Nelson DB, Rice T, Neu J: Increased risk of gastrointestinal perforations in neonates mechanically ventilated with either face mask or nasal prongs. Pediatr 1985, 76(3):406-410.

98. Greenough A, Dimitriou G, Prendergast M, Milner AD: Synchronized mechanical ventilation for respiratory support in newborn infants. Cochrane Database Syst Rev 2008, 1(1):CD000456.

99. Lemyre B, Davis PG, De Paoli AG: Nasal intermittent positive pressure ventilation (NIPPV) versus nasal continuous positive airway pressure (NCPAP) for apnea of prematurity. Cochrane Database Syst Rev 2002, 1(1): CD002272.

100. Ho J, Subramaniam P, Henderson-Smart D, Davis P: Ho J, Subramaniam P, Henderson-Smart DJ, Davis PG. Continuous distending pressure for respiratory distress in preterm infants. Cochrane Database Syst Rev 2002, 2(2):CD002271.

101. Mills JF, Tudehope D: Fibreoptic phototherapy for neonatal jaundice. Cochrane Database Syst Rev 2001, 1(1):CD002060.

102. Thayyil S, Milligan DW: Single versus double volume exchange transfusion in jaundiced newborn infants. Cochrane Database Syst Rev 2006, 4(4):CD004592.

103. Jones G, Steketee RW, Black RE, Bhutta ZA, Morris SS, Bellagio Child Survival Study Group: How many child deaths can we prevent this year? Lancet 2003, 362(9377):65-71.

104. Darmstadt GL, Bhutta ZA, Cousens S, Adam T, Walker N, de Bernis L, Lancet Neonatal Survival Steering Team: Evidence-based, cost-effective interventions: how many newborn babies can we save? Lancet 2005, 365(9463):977-988.

105. Bhutta ZA, Das JK, Rizvi A, Gaffey MF, Walker N, Horton S, Webb P, Lartey A, Black RE, Lancet Nutrition Interventions Review Group, Maternal and Child Nutrition Study Group: Evidence-based interventions for improvement of maternal and child nutrition: what can be done and at what cost? Lancet 2013, 382(9890):452-477.

106. Bhutta ZA, Yakoob MY, Lawn JE, Rizvi A, Friberg IK, Weissman E, Buchmann E, Goldenberg RL: Stillbirths: what difference can we make and at what cost? Lancet 2011, 377(9776):1523-1538.

107. Kerber KJ, de Graft-Johnson JE, Bhutta ZA, Okong P, Starrs A, Lawn JE: Continuum of care for maternal, newborn, and child health: from slogan to service delivery. Lancet 2007, 370(9595):1358-1369.

108. Khadka N: Increasing Access to Quality Postnatal Care: Findings From PNC Project in Nepal. MotherNewBorNews; 2005.

doi:10.1186/1742-4755-11-S1-S3

Cite this article as: Salam et al:: Essential childbirth and postnatal interventions for improved maternal and neonatal health. Reproductive Health 2014 11(Suppl 1):S3. 